\section{Factors influencing sexual function in women with genital prolapse}

Maxime Marcelli, Gilles Karsenty, Jean P. Estrade, Ludovic Cravello, Gérard Serment, Marc Gamerre, Aubert Agostini

Assistance Publique des Hôpitaux de Marseille, Gynecological and Obstetrical Department of Hôpital de la Conception and Urologic, Department of Sainte-Marguerite, Marseille, France

\section{Abstract}

Background. To evaluate the impact of the different types of genital prolapse and associated factors, on sexual quality of life in women presenting a genital prolapse.

Design and methods. Forty-four women were included in this prospective observational study. We collected clinical data. Genital prolapse was quantified according to the Pelvic Organ Prolapse Quantification scale (POP-Q). Sexual function was evaluated using a validated questionnaire (PISQ-12). Statistical analysis between POP-Q stages, clinical characteristics and PISQ-12 scores was undertaken.

Results. A history of abdominal surgery significantly decreases the sexual quality of life $(\mathrm{P}=0.03)$. $\mathrm{PISQ}-12$ scores were poorly affected by the type and the severity of genital prolapse.

Conclusions. The only factor influencing sexual quality of life was a history of previous abdominal surgery. The type and severity of genital prolapse did not influence sexual function. These results must be confirmed further studies with a higher sample size.

\section{Introduction}

Genital prolapse is a highly prevalent disorder $^{1}$ that can affect up to $45 \%$ of postmenopausal women and $33 \%$ of premenopausal women with an history of vaginal delivery. ${ }^{2,3}$ Therefore it concerns a large number of women sexually active.

For these patients, having a genital prolapse means a decrease of sexual quality of life. ${ }^{4-6}$

There is few data looking at the factors that influence sexual quality of life in women affected by a genital prolapse. Clinical presentation of the prolapse, defined by the POP-Q classification, is one of the first element to consider, as well as associated factors (medical, surgical and obstetrical history and stress urinary incontinence). The aim of this study is to evaluate how type and severity of genital prolapse and associated factors influences sexual quality of life in women with genital prolapse.

\section{Design and Methods}

This prospective observational study was conducted within the Gynecological and Obstetrical department of Hôpital de la Conception and the Urologic department of Sainte-Marguerite (Assistance publique des hôpitaux de Marseille) between January 2006 and March 2008. The studied population was composed of heterosexual women consulting for genital prolapse and for whom laparoscopic sacrocolpopexy was indicated. Informed consent was obtained from all the patients participating in the study. The ethical board on medical research as defined by the French law was consulted. The commitee in accordance with the French public health law considered that its approval was not necessary since the management was standard and did not lead to any additional, unusual or innovative diagnostic or follow-up procedures.

Data collected was: age, body mass index, gestity, parity, delivery mode, previous surgical treatment (hysterectomy, genital prolapse repair, abdominal surgery) and presence of stress urinary incontinence..$^{4,7}$ Genital pro-
Correspondence: Maxime Marcelli, Hôpital de la Conception, 270 boulevard de Sainte Marguerite, Marseille 13008, France.

Tel. +33.4.91380000.

E-mail: maximemarcelli@free.fr

Key words: genital prolapse, PISQ-12, POP-Q sexual quality of life.

Received for publication: 12 September 2010.

Revision received: 27 June 2011.

Accepted for publication: 30 June 2011.

This work is licensed under a Creative Commons Attribution NonCommercial 3.0 License (CC BYNC 3.0).

(C) Copyright M. Marcelli et al., 2011

Licensee PAGEPress, Italy

Urogynaecologia 2011; 25:e1

doi:10.4081/uij.2011.e1

lapse was quantified according to the Pelvic Organ Prolapse Quantification scale (POP-Q), as described by the International Continence Society (ICS). ${ }^{9}$ A validated and reliable autoquestionnaire was distributed to every patient to evaluate their sexual quality of life..$^{10,11} \mathrm{~A}$ sexual quality of life score was established according to the data collected by the questionnaire (PISQ-12) and following the method described at the bottom of page of the English version. ${ }^{10}$ Groups of patients were constituted according to clinical characteristics, affected

Table 1. Comparison of the PISQ-12 scores according to the clinical characteristics.

\begin{tabular}{|c|c|c|}
\hline $\begin{array}{l}\text { Clinical characteristics } \\
\text { Mean and standard deviation }\end{array}$ & PISQ-12 score & $\mathbf{P}$ \\
\hline $\begin{array}{l}\text { Abdominal surgery history } \\
\text { Yes } \\
\text { No }\end{array}$ & $\begin{array}{l}18.3 \pm 7.2 \\
13.4 \pm 5.8\end{array}$ & 0.03 \\
\hline $\begin{array}{l}\text { Surgical treatment for genital } \\
\text { prolapse history } \\
\text { Yes } \\
\text { No }\end{array}$ & $\begin{array}{l}17.6 \pm 7.4 \\
14.5 \pm 6.4\end{array}$ & 0.24 \\
\hline $\begin{array}{l}\text { Hysterectomy history } \\
\text { yes } \\
\text { no }\end{array}$ & $\begin{array}{l}20.8 \pm 8.7 \\
14.9 \pm 6.4\end{array}$ & 0.14 \\
\hline $\begin{array}{l}\text { Instrumental delivery } \\
\text { yes } \\
\text { no }\end{array}$ & $\begin{array}{l}14.4 \pm 4.8 \\
15.9 \pm 7.3\end{array}$ & 0.63 \\
\hline $\begin{array}{l}\text { Stress urinary incontinence } \\
\text { yes } \\
\text { no }\end{array}$ & $\begin{array}{l}17.4 \pm 7.8 \\
15.0 \pm 6.4\end{array}$ & 0.26 \\
\hline $\begin{array}{l}\text { Gestity } \\
\begin{array}{l}x=\leq 1 \\
y=\geq 2\end{array}\end{array}$ & $\begin{array}{l}18.6 \pm 8.0 \\
15.2 \pm 6.6\end{array}$ & 0.38 \\
\hline $\begin{array}{l}\text { Parity } \\
\quad \leq 1 \\
\geq 2\end{array}$ & $\begin{array}{l}18.3 \pm 7.5 \\
15.1 \pm 6.6\end{array}$ & 0.29 \\
\hline $\begin{array}{l}\text { BMI } \\
<25 \\
\geq 25\end{array}$ & $\begin{array}{l}15.4 \pm 8.0 \\
16.3 \pm 4.3\end{array}$ & 0.47 \\
\hline
\end{tabular}

BMI, body mass index 
location, POP-Q stage and the questionnaire mean scores for each of these groups were then compared. The statistical tools used were the ANOVA or Kruskal-Wallis tests according to their applicability on the data. Correlations were made between the parametric or non parametric quantitative variables. The statistical analyses were performed using the SPSS version 15.0 software package (SPSS Inc., Chicago, IL, USA). The statistical significance threshold was defined as $\mathrm{P}<0.05$.

\section{Results}

Sixty-eight women were eligible to participate in the study. Seventeen women did not want to answer the sexual quality of life questionnaire or incompletely filled it out and 7 women were not sexually active. Finally, 44 women were included in the study. Mean age was $55.3 \pm 9.4$ years. Thirty-four women were menopausal and none of them was treated by hormones replacement therapy. Eleven women (25\%) had a stress urinary incontinence. One woman was nulliparous and 35 women (79.5 \%) had given birth at least twice. Nine women (20.5\%) had instrumental delivery and one (2\%) had a cesarean section. Five women (11.4\%) had a previous hysterectomy. Nineteen women (43.2\%) had an abdominal surgery history: 13 laparoscopy (4 appendicitis; 5 cholecystectomy; 3 for pelvic pain; 1 adjustable gastric banding) and 6 laparotomy (1 for inguinal hernia; 5 for hysterectomy). Fifteen patients had a previous surgical treatment for genital prolapse: 9 women treated by vaginal approach (6 sacrospinofixation; 3 cystocele repair); 2 laparotomy for sacrocolpopexy and 4 laparoscopy for sacrocolpopexy). Thirteen patient $(29.5 \%)$ had a stress urinary incontinence associated to genital prolapse. Age did not influence PISQ-12 score significantly. The only studied clinical variable which significantly influenced the sexual quality of life was a previous abdominal surgery $(18.3 \pm 7.2$ vs $13.4 \pm 5.8)(\mathrm{P}=0.03)$. The analysis of PISQ-12 scores $v s$ clinical characteristics is presented in Table 1.

After distribution of the patients according to the lowest reference point, the PISQ-12 scores were compared for a lowest reference point (alone or equally with other points) versus all other lowest reference points. This comparison is reported in Table 2.

The PISQ-12 scores were successively compared according to the affected reference point then according to the stage of every reference point (Ba, Bp, C-D) and finally according to the total stage. Results are reported in Table 3.

\section{Conclusions}

We chose the POP-Q system of quotation as well as the PISQ-12 questionnaire of evaluation of the sexual quality of life because they are two measuring instruments validated in literature. ${ }^{12-15}$ The clinical examination (POPQ) done here is accessible and reproducible by any practitioner, and the questionnaire of evaluation of the sexual quality of life (PISQ-12) can be given to any patient presenting in consultation for symptoms in connection with a genital prolapse because it is brief and easy to perform. Patients presenting a genital prolapse have a less good sexual quality of life than those who do not. ${ }^{5,6}$ Among the patients presenting a genital prolapse, a previous study reported an impaired sexual quality of life (estimated by the PQO-L) in case of severe genital prolapse (high the POP-Q stage).$^{16}$ In our study we did not find this result by using the validated PISQ-12 sexual quality of life questionnaire. However, our results needs to be confirmed with a more important sample size. The association of a stress urinary incontinence to a genital prolapse has been reported to alter sexual function..$^{17,18}$ The fact that 25 patients had a stress urinary incontinence may be a confounding variable. In our study we do not find this trend by using the PISQ-12 $(\mathrm{P}=0.26)$. Evaluation of the sexual quality of life by the PISQ-12 score according to the POP$Q$ genital prolapse quotation system and according to the factors associated with the genital prolapse is poorly informed in the literature. To our knowledge very few study having put in direct relation the POP-Q stage and the PISQ-12 score. ${ }^{19}$ According to our study, a history of abdominal surgery decreases the sexu-

Table 2. PISQ-12 scores compared for a lowest reference point (alone or equally with other points) $v s$ all other lowest reference points.

\begin{tabular}{|c|c|c|}
\hline & $\begin{array}{l}\text { SQ-12 sed } \\
\text { I standard }\end{array}$ & $\mathbf{P}$ \\
\hline $\begin{array}{l}\text { Ba } \\
\text { Is the lowest reference point }(\mathrm{n}=33) \\
\text { Is not the lowest reference point }(\mathrm{n}=11)\end{array}$ & $\begin{array}{l}17.06 \pm 6.8 \\
12.73 \pm 4.8\end{array}$ & 0.06 \\
\hline $\begin{array}{l}\text { Bp } \\
\text { Is the lowest reference point }(n=18) \\
\text { Is not the lowest reference point }(n=26)\end{array}$ & $\begin{array}{l}14.56 \pm 6.3 \\
16.96 \pm 6.7\end{array}$ & 0.23 \\
\hline $\begin{array}{l}\text { C-D } \\
\text { Is the lowest reference point }(n=8) \\
\text { Is not the lowest reference point }(n=36)\end{array}$ & $\begin{array}{l}17.6 \pm 3.42 \\
15.6 \pm 7.14\end{array}$ & 0.45 \\
\hline
\end{tabular}

Table 3. PISQ-12 scores successively compared according to the affected reference point then according to the stage of every reference point (Ba. Bp. C-D) and finally according to the total stage.

\begin{tabular}{|c|c|c|c|c|}
\hline 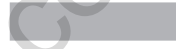 & Number & Mean & Standard deviation & P \\
\hline \multicolumn{5}{|c|}{ Comparison of PISQ-12 score according to one or several affected reference points } \\
\hline $\mathrm{Ba}$ & 10 & 16.9 & 8.7 & 0.42 \\
\hline C-D & 4 & 12.8 & 5.5 & \\
\hline $\mathrm{Ba}+\mathrm{Bp}$ & 7 & 18.3 & 4.9 & \\
\hline $\mathrm{Ba}+\mathrm{C}-\mathrm{D}$ & 11 & 16.5 & 8.2 & \\
\hline $\mathrm{Ba}+\mathrm{Bp}+\mathrm{C}-\mathrm{D}$ & 12 & 13.6 & 4.7 & \\
\hline \multicolumn{5}{|c|}{ Comparison of the stage for the point Ba according to the PISQ-12 score } \\
\hline Stage 0 and 1 & 6 & 15.66 & 6.40 & 0.86 \\
\hline Stage 2 & 21 & 16.04 & 6.91 & \\
\hline Stage 3 & 15 & 14.53 & 6.54 & \\
\hline Stage 4 & 2 & 21.5 & 12.02 & \\
\hline \multicolumn{5}{|c|}{ Comparison of the stage for the point Bp according to the PISQ-12 score } \\
\hline Stage 0 and 1 & 28 & 16.32 & 7.65 & 0.78 \\
\hline Stage 2 & 14 & 14.71 & 5.41 & \\
\hline Stage 3 & 2 & 14.50 & 2.12 & \\
\hline \multicolumn{5}{|c|}{ Comparison of the stage for the point C-D according to the PISQ-12 score } \\
\hline Stage 0 and 1 & 18 & 17.66 & 6.92 & 0.20 \\
\hline Stage 2 & 5 & 15.26 & 6.28 & \\
\hline Stage 3 & 8 & 11.87 & 4.64 & \\
\hline Stage 4 & 3 & 16.66 & 11.93 & \\
\hline \multicolumn{5}{|c|}{ Comparison of the total POP-Q stage according to the PISQ-12 score } \\
\hline Stage 0 and 1 & 1 & 24.00 & - & 0.29 \\
\hline Stage 2 & 18 & 17.22 & 6.81 & \\
\hline Stage 3 & 22 & 14.00 & 5.96 & \\
\hline Stage 4 & 3 & 16.66 & 11.93 & \\
\hline
\end{tabular}


al quality of life $(\mathrm{P}=0.03)$ while age, body mass index, gestity, parity, delivery mode, hysterectomy history, surgical treatment for genital prolapse history are not significantly connected to sexual quality of life. In literature it is reported that a history of hysterectomy or genital prolapse surgery decreases sexual quality of life. ${ }^{4}$ By using the PISQ-12 we do not find similar results.

The fact that only one of reference points (Ba; Bp; CD) is affected or that some of these points are affected at the same time does not seem to modify significantly the score of the PISQ-12. Thus a particular type of genital prolapse does not seem to influence the sexual quality of life more than another one, but this needs to be verified by studies with a higher sample size. Sexual quality of life of patients presenting a genital prolapse in which reference point $\mathrm{Ba}$ is lower than reference points $\mathrm{Bp}$ and $\mathrm{CD}$, tends to be more decreased than sexual quality of life of patients presenting a genital prolapse in which reference points $\mathrm{Bp}$ or $\mathrm{CD}$ are lower than other reference points $(\mathrm{P}=0.06)$. In conclusion our study did not reveal any relation between type and severity of prolapse and sexual quality of life. The only factor decreasing sexual quality of life was the presence of a history of abdominal surgery but these results must be confirmed by further works with a higher sample size.

\section{References}

1. DeLancey J0. The hidden epidemic of pelvic floor dysfunction: achievable goals for improved prevention and treatment. Am J Obstet Gynecol 2005;192:1488-95.

2. Sentilhes L, Berthier A, Sergent F, et al. Sexual function in women before and after transvaginal mesh repair for pelvic organ prolapse. Int Urogynecol J Pelvic Floor Dysfunct 2008;19:763-72.

3. Rogers RG, Kammerer-Doak D, Darrow A, et al. Does sexual function change after surgery for stress urinary incontinence and/or pelvic organ prolapse? A multicenter prospective study. Am J Obstet Gynecol 2006;195:1-4.

4. Ghielmetti T, Kuhn P, Dreher EF, Kuhn A. Gynaecological operations: do they improve sexual life? Eur J Obstet Gynecol Reprod Biol 2006;129:104-10.

5. Novi JM, Jeronis S, Morgan MA, Arya LA. Sexual function in women with pelvic organ prolapse compared to women without pelvic organ prolapse. J Urol 2005;173: 1669-72.

6. Achtari C, Dwyer PL. Sexual function and pelvic floor disorders. Best Pract Res Clin Obstet Gynaecol 2005;19:993-1008.

7. Brubaker L, Handa VL, Bradley CS, et al. Pelvic Floor Disorders Network. Sexual function 6 months after first delivery. Obstet Gynecol 2008;111:1040-4.

8. Jelovsek JE, Barber MD. Women seeking treatment for advanced pelvic organ prolapse have decreased body image and quality of life. Am J Obstet Gynecol 2006; 194:1455-61.

9. Messelink B, Benson T, Berghmans B, et al. Standardization of terminology of pelvic floor muscle function and dysfunction: report from the pelvic floor clinical assessment group of the International Continence Society. Neurourol Urodyn 2005;24:374-80.

10. Rogers RG, Coates KW, Kammerer-Doak D, et al. A short form of the Pelvic Organ Prolapse/Urinary Incontinence Sexual Questionnaire (PISQ-12). Int Urogynecol J Pelvic Floor Dysfunct 2003;14:164-8.

11. Rogers RG, Kammerer-Doak D, Villarreal A, et al. A new instrument to measure sexual function in women with urinary incon- tinence or pelvic organ prolapse. Am J Obstet Gynecol 2001;184:552-8.

12. de Barros Moreira Lemos NL, Flores Auge AP, Lunardelli JL, et al. Optimizing pelvic organ prolapse research. Int Urogynecol J Pelvic Floor Dysfunct 2007;18:609-11.

13. Hall AF, Theofrastous JP, Cundiff GW, et al. Interobserver and intraobserver reliability of the proposed International Continence Society, Society of Gynecologic Surgeons, and American Urogynecologic Society pelvic organ prolapse classification system. Am J Obstet Gynecol 1996;175:146770; discussion 1470-1.

14. De Vita D, Araco F, Gravante G, et al. Vaginal reconstructive surgery for severe pelvic organ prolapses: a uterine-sparing technique using polypropylene prostheses. Eur J Obstet Gynecol Reprod Biol 2008;139:245-51.

15. Nguyen JN, Burchette RJ. Outcome after anterior vaginal prolapse repair: a randomized controlled trial. Obstet Gynecol 2008;111:891-8.

16. Digesu GA, Chaliha C, Salvatore S, et al. The relationship of vaginal prolapse severity to symptoms and quality of life. BJOG 2005;112:971-6.

17. Morgan DM, Dunn RL, Stoffel JT, et al. Are persistent or recurrent symptoms of urinary incontinence after surgery associated with adverse effects on sexual activity or function? Int Urogynecol J Pelvic Floor Dysfunct 2008;19:509-15.

18. Ellerkmann RM, Cundiff GW, Melick CF, et al. Correlation of symptoms with location and severity of pelvic organ prolapse.Am J Obstet Gynecol 2001;185:1332-7; discussion 1337-8.

19. Tok EC, Yasa O, Ertunc D, et al. The effect of pelvic organ prolapse on sexual function in a general cohort of women. J Sex Med 2010; 7:3957-62. 